\title{
RELIGIÃO, FEMINISMO E ISLÃ: PERSPECTIVAS DO FEMINISMO ISLÂMICO
}

\author{
Maria Eduarda Antonino Vieira*
}

\begin{abstract}
RESUMO
Este artigo tem o intuito de apresentar um dos objetivos de minha dissertação ${ }^{1}$ de mestrado sobre como as mulheres muçulmanas ${ }^{2}$ participam e percebem a construção dos seus direitos no contexto ocidental europeu. Dessa forma, delineio como ocorre o debate teórico entre "a religião e o feminismo" focando especialmente os discursos das feministas islâmicas (feminismo religioso) e do feminismo ocidental (secular). O feminismo é um movimento social, político, econômico e intelectual que tem sido definido de várias maneiras há mais de 200 anos. O único consenso atual é de que não há feminismo algum, mas, na verdade, muitas tradições dentro de um movimento maior dedicado à obtenção de capital para as mulheres.
\end{abstract}

Palavras-chave: Religião. Feminismo. Islã.

\section{RELIGION, FEMINISM AND ISLAM: PERSPECTIVES OF ISLAMIC FEMINISM}

\begin{abstract}
This article aims to present one of the objectives of my master's thesis on how muslim women participate and perceive the construction of their rights in the Western European context. In this way, I will outline how the theoretical debate between "religion and feminism" focuses especially on the discourses of Islamic feminists (religious
\end{abstract}

* Mestra em Ciência Política pela Universidade Federal de Pernambuco (UFPE). Graduada em Relações Internacionais pela Faculdade Damas (ARIC).

1 Dissertação defendida no mestrado do Programa de Pós-Graduação em Ciência Política da Universidade Federal de Pernambuco exposto no dia 12 de junho de 2018.

2 Quando se fala de "mulheres muçulmanas", é necessário reforçar que a nomenclatura foi utilizada, exclusivamente, para a construção de uma categoria analítica e que elas não são, de forma alguma, um monolito. E, nesta pesquisa, essa categoria é composta apenas de mulheres que dominam o idioma nativo dos contextos nas quais estão inseridas. 
feminism) and Western (secular) feminism. Feminism is a social, political, economic and intellectual movement that has been defined in many ways for more than 200 years. The only current consensus is that there is no feminism, but indeed many traditions within a larger movement dedicated to raising capital for women.

Keywords: Religion. Feminism. Islam.

\title{
RELIGIÓN, FEMENISMO Y ISLÁ: PERSPECTIVAS DEL FEMENISMO ISLÁMICO
}

\begin{abstract}
RESUMEN
Este artículo tiene el propósito de presentar uno de los objetivos de mi disertación de maestría sobre cómo las mujeres musulmanas participan y perciben la construcción de sus derechos en el contexto occidental europeo. De esta forma, voy a delinear como ocurre el debate teórico entre "la religión y el feminismo", enfocándose especialmente en los discursos de las feministas islámicas (feminismo religioso) y del feminismo occidental (secular). El feminismo es un movimiento social, político, económico e intelectual que ha sido definido de varias maneras desde hace más de 200 años. El único consenso actual es que no hay feminismo, pero, en realidad, muchas tradiciones dentro de un movimiento mayor dedicado a la obtención de capital para las mujeres.
\end{abstract}

Palabras claves: Religión. Feminismo. Islam.

\section{INTRODUÇÃO}

As mulheres muçulmanas são hoje parte integrante da comunidade europeia, muitas vezes colocadas no centro dos debates políticos, religiosos e de gênero, por conta da sua visibilidade religiosa. O véu islâmico ${ }^{3}$ tornou-se um símbolo antiocidental e antifeminista. O tópico "mulher e Islã" continua sendo rotineiramente interpretado na Europa Ocidental de maneira reducionista, preconceituosa e fetichizada, sendo as mulheres muçulmanas observadas como passivas, submissas, inativas,

3 O que é chamado de "véu", em inglês, não corresponde a qualquer único termo em árabe. Veiling tradicionalmente é exigido das mulheres muçulmanas quando aparecem em público e tomou diversas formas de acordo com a configuração cultural: a burca afegã; o xador iraniano, a máscara facial da região do Golfo; e o lenço cobrindo a parte inferior da face, no norte da África. O hijab é apenas um elemento no uniforme contemporâneo urbano islâmico, ou alziyy al-Islami, como é conhecido (Dunya MAUMOON, 1999). 
altamente dependentes por conta da vestimenta, da poligamia e da lei da herança, entre outros temas que são facilmente prejulgados pelo Ocidente. As muçulmanas terminam sendo pouco percebidas, tornando-se seres humanos "invisíveis". Quando são observadas, são entendidas como pessoas sem utilidade ou valor para a sociedade, em contraste com as imagens das mulheres ocidentais, que são colocadas como educadas, empoderadas e liberais. Tudo isso está fortemente amarrado à dicotomia "nós" versus "elas", que estabelece papéis predefinidos e reforçam imagens estereotipadas das muçulmanas, resultando, também, na apropriação do seu poder decisório.

É importante entender que as mulheres muçulmanas fazem parte de uma Europa Ocidental onde vivem quase vinte milhões de seguidores do Islã. Essa parcela de muçulmanos tem crescido em cerca de um ponto percentual por década nos últimos 25 anos, passando de $4 \%$ em 1990 para 6\% em 2010, ou seja, eram menos de 10 milhões em 1990, para aproximadamente 17 milhões, em 2010 (PEW RESEARCH CENTER, 2011), tornando-se o Islã a maior religião minoritária da região. Tais mudanças demográficas produzem adversidades diante do crescimento populacional. O Islã passa a ser uma significativa força social, política e religiosa na Europa Ocidental e os Estados europeus enfrentam desafios importantes sobre como acomodar os direitos religiosos, políticos e sociais desses seguidores, muitos dos quais não são imigrantes, mas cidadãos e cidadãs dos diferentes países.

Existe uma tendência, principalmente da mídia, de englobar os muçulmanos, especialmente as mulheres, como um monólito sem voz. Há muitos fatores que influenciam a visão deturpada do Ocidente para com as mulheres muçulmanas. Um dos mais importantes tem sido a tendência em agregar as mulheres muçulmanas em um grande grupo e vê-las como clones homogêneos umas das outras, deixando de lado as características geográficas, políticas, sociais, históricas e doutrinárias que moldam suas vidas em diferentes partes do mundo e as diferenciam, às vezes marcadamente (Saimah ASHRAF, 1999). Tendência que, por exemplo, não acontece em relação à mulheres ocidentais. Uma francesa dificilmente seria confundida com uma mexicana e uma brasileira dificilmente seria classificada como uma italiana, mesmo que todas fossem católicas e tivessem o mesmo sistema de crenças, por exemplo. 
No entanto, deve-se admitir que existem ainda vários aspectos da legislação islâmica (sharī 'ah) que estão afetando seriamente a construção, pelas próprias muçulmanas, dos seus direitos. Por exemplo, pouco mudou em relação a problemas como casamentos forçados, divórcio, poligamia, sexualidade e honra familiar (masculina) (AL-HIBRI, 2002). A interpretação patriarcal, socialmente conservadora, em relação a essas questões, é certamente responsável por muitos dos problemas contemporâneos das muçulmanas no universo islâmico e não islâmico. Apesar das várias tentativas de reformar essas leis, tais problemas - inegáveis em partes do mundo muçulmano - alimentam visões ocidentais estereotipadas. Essas imagens são perpetuadas e reforçadas, fazendo que as mulheres muçulmanas não sejam vistas como protagonistas das suas vidas, muito menos da arena política.

Sem contar as velhas experiências e concepções coloniais das mulheres muçulmanas (projetadas no final do século XVIII), responsáveis por nutrir um sentimento de superioridade, retratada na fala, por exemplo, do Lorde Cromer, no Egito, "estou aqui para libertar as mulheres muçulmanas, estou aqui para libertá-las do Islã" e o "libertar" significava que as mulheres muçulmanas iriam abdicar da sua religião e adotar um modo de vida ocidental (Rana KABBANI, 1992). Essa missão libertadora continua nas sociedades contemporâneas ocidentais, onde percepções das mulheres muçulmanas como não sujeitos foram retomadas e reforçadas por boa parte do próprio feminismo ocidental secular, sendo o colonial feminism visto como uma política de governo sobre as mulheres (Leila AHMED, 1992).

Os governos conseguem respaldo das feministas ocidentais que continuam a propagar que, para as muçulmanas serem bem-sucedidas e ganharem status e o respeito do feminismo secular, elas devem deixar de lado sua cultura religiosa em sua totalidade e abraçar com todo coração o modo de vida ocidental. Propagando uma verdade absoluta como sinônimo de empoderamento, movimentação que termina não ajudando as imagens das mulheres muçulmanas, nem de qualquer muIher religiosa. Essas feministas tendem a ignorar questões relevantes como a centralidade da espiritualidade islâmica ou do Islã como uma questão de identidade. Em muitos casos, resolvendo as "violações" 
dos direitos da mulher no mundo muçulmano à luz de práxis que são estranhas à cultura islâmica (Orit AVISHAI, 2008; Niamh REILLY, 2011).

A polêmica opção/escolha pelo uso da vestimenta é um tema complexo que envolve não só crenças religiosas, mas também elementos sociais, culturais e políticos. Como reconhece Leila Ahmed (1992:152), nas sociedades ocidentais a imagem do hijab ou véu adquiriu uma função simbólica, como "o marcador mais visível das diferenças e inferioridade das sociedades islâmicas, um símbolo de submissão das mulheres e atraso do Islã". Entretanto, outros estudos já mostram que a utilização da vestimenta pode ser interpretada com diversos enquadramentos. Variam de um ato político, um meio de afirmação da identidade islâmica e até a modéstia em relação a Allah (Margot BADRAN, 2009). As jovens mulheres turcas, por exemplo, estão usando o hijab como o símbolo do feminismo islâmico, que contradiz as imagens ocidentais do véu como sinal de subjugação (Philip SMUCKER, 1998).

Este trabalho é importante pela necessidade de se amplificar a compreensão sobre os campos da religião e gênero que ainda se esforçam para sair da condição de outsiders na academia. Pesquisadores dessa temática sublinham que as produções brasileiras relativas às religiões não mencionam a temática de gênero, enquanto os balanços na área de estudos de gênero não contemplam a produção acadêmica no campo dos estudos da religião. É esse desconhecimento mútuo que se denomina invisibilidade. Apesar dos impactos do Feminismo sobre as religiões, o desenvolvimento de uma análise feminista das religiões que tome em conta as diferentes formas pelas quais as relações entre os gêneros moldam práticas, representações e discursos religiosos, é, no mínimo, bastante lento. Por sua vez, os estudos da religião não absorvem as proposições de gênero de maneira significativa e sistemática. A experiência de muitas mulheres religiosas oscila entre a afirmação de sua fé religiosa e a necessidade de defender os mais elementares de seus direitos, em busca da própria autonomia (Maria José ROSADO-NUNES, 2017).

O trabalho também busca contribuir para um reconhecimento feminista do que a fé desempenha na vida das mulheres contemporâneas. Ao invés de olhar como as instituições religiosas veem as mulheres, 
examinaremos o que as mulheres religiosas islâmicas nos dizem sobre direitos religiosos, igualdade de gênero, identidade e feminismo. Neste estudo, privilegiam-se as vozes das mulheres religiosas e seus pontos de vista, ao invés de textos e práticas que podem ser considerados como "autoritários" ou "ilegítimos" nas representações de suas tradições religiosas. Adotando uma perspectiva bottom-up para analisar as relações entre religião e gênero, examinando como as mulheres vivem, praticam e negociam sua fé e identidade na vida cotidiana, a partir do seu engajamento cívico e político.

\section{RELIGIÃO E GÊNERO}

As mulheres muçulmanas estão no centro dos debates públicos sobre o papel da religião, tradição e modernidade, secularismo e emancipação, e muitas vezes são apontadas como vítimas da opressão atribuídas ao Islã. Todavia, elas, desde sempre, estão desenvolvendo uma afirmação de autonomia individual que não vai de mãos dadas com o secularismo, na verdade, adotam um processo que não rejeita tradição, mas que tem dentro delas uma peça central para desafiar as estruturas. Dessa forma, é importante entender que as ideias libertárias não surgiram apenas no meio das mulheres seculares, as mulheres religiosas, suas crenças e práticas também foram temas de debate no âmbito de diferentes tradições religiosas e congregações (Gita SAHGAL e Nira YUVAL-DAVIS, 1992; Jane BAYES e Nayereh TOHIDI, 2001; Sukhwant DHALIWAL e Nira YUVAL-DAVIS, 2014).

$\mathrm{Na}$ escola feminista, as estudiosas têm há tempos "visualizado a consciência de gênero como nascida fora da crença e da experiência religiosa, além de ser precursora do primeiro movimento dos direitos da mulher" (BRAUDE, 2004, p. 569). Não há quase menção alguma às mulheres religiosas em movimentos ou contextos ativistas. Pela carência desses relatos, Margot Badran destaca o ativismo histórico das europeias e outras feministas religiosas cristãs, muçulmanas e judias em contextos nacionais e internacionais (ver, por exemplo, Margot BADRAN, 2009; Line Nyhagen PREDELLI, 2003; BRAUDE, 2004), bem como, o ativismo feminista contemporâneo das mulheres cristãs e muçulmanas nas sociedades europeias, pois: 
...a relação entre as mulheres, religião e mudança social tomou uma grande variedade de formas. As mulheres têm atuado em movimentos religiosos que eram revolucionários em suas implicações. As mulheres têm atuado em movimentos revolucionários que eram religiosos (pelo menos parcialmente) em sua inspiração. As mulheres se inspiraram individualmente na religião para participar de movimentos que lutavam por mudanças na sociedade; mulheres têm sido solicitadas a lutar por mudanças sociais e mudanças na religião. A religião tem sido um instrumento de libertação para as mulheres. Da mesma forma como se torna um instrumento de opressão social das mulheres (Yvonne YAZBECK-HADDAD, 1998: 21).

Mulheres religiosas e religiosas feministas têm sido parte da história contemporânea dos movimentos de mulheres em todo o mundo. Ao lado das não religiosas, elas têm lutado por seus direitos e por igualdade, enquanto também se identificam com sua fé religiosa pessoal. Para algumas feministas, a crença e a prática religiosa das mulheres têm sido uma questão impugnada, enquanto outras feministas têm aceito, abraçado ou sido indiferentes à religião. Os debates sobre religião e gênero tiveram lugar entre feministas desde as primeiras mobilizações de mulheres, de fins do século XIX ao início do século XX. Em contextos europeus, as três religiões principais do mundo têm sido analisadas pelas feministas religiosas e não religiosas, e a questão da crença religiosa coexistir com valores feministas tem sido debatida vigorosamente (Sue MORGAN, 2002; Line Nyhagen PREDELLI, 2003).

Uma tendência negativa é abordar o estudo da relação entre religião e gênero em termos de uma única e reducionista problemática: "a religião é boa ou ruim para as mulheres? Ela reforça o patriarcado ou pode miná-lo?" (Linda WOODHEAD, 2002: 384). Há uma série de problemas sobre essa abordagem temática. Um deles é que a pergunta é muito ampla e muito contundente para fazer justiça às formas extremamente variadas de religião ou às maneiras sutis, complexas e altamente específicas em que as mulheres habitam, subvertem e negociam com elas. Outra questão é o critério de bondade ou maldade (equiparado à libertação e opressão). Igualmente complicado e complexo sobre vários pontos, principalmente, sobre a diferença cultural e histórica (IBIDEM, 2002: 384-386). A luta interna pela igualdade de gênero em 
seus próprios contextos religiosos não pode ser deixada de lado. Dubravka Žarkov argumenta:

...o papel da fé na vida cotidiana de mulheres é muitas vezes ignorado, ainda mais, é visto como símbolo do tradicionalismo e atraso, obstáculo à emancipação e raramente reconhecido como uma inspiração na luta das mulheres por justiça social e os direitos das mulheres (2015: 6).

As teorizações das feministas religiosas, bem como, de aliadas não secularistas, sugerem que a religião pode, sim, contribuir para a luta pela justiça, inclusive a luta pela igualdade entre os sexos e a ideia de que as feministas religiosas são potenciais aliadas das feministas seculares (Martha NUSSBAUM, 2012). Elas criticam fortemente os binarismos, retratando-o como falsos e opressivos. Niamh Reilly e Joan Scott, que não são particularmente identificadas com posições religiosas, sugerem que o binário "religioso versus secular" está atualmente implicado em novas formas de violência do Estado contra as minorias. No contexto ocidental, os muçulmanos, particularmente as mulheres, são direcionados e submetidos a interrogatório, vigilância e outras formas de violência e controle estatal. Além disso, elas reconhecem que a religião pode ser utilizada para legitimar desigualdades e a discriminação com as mulheres. No entanto, elas rejeitam a ideia de que a religião é por necessidade patriarcal (Niamh REILLY, 2011: 14-18; Joan SCOTT, 2007).

As mulheres podem experimentar tanto empoderamento como subordinação dentro de contextos religiosos. A religião, portanto, pode ser analisada tanto como um recurso quanto como barreira aos direitos das mulheres, ou à sua participação e pertencimento dentro e fora das comunidades religiosas. Da mesma forma, a sociedade secular também não é garantia de igualdade política, social ou econômica entre mulheres e homens (Linell CADY e Tracy FESSENDEN, 2013; Niamh REILLY; Stacey SCRIVER, 2013). Em consequência, os direitos das mulheres e a igualdade de gênero devem ser estudados em contextos particulares que considerem suas oportunidades e participação em uma perspectiva ampla, incluindo a religião. Gema Martín Muñoz (1999: 13) ressalta que: 
...as sociedades ocidentais seculares têm sido mal informadas e tornam-se tendenciosas quando não entendem que o problema das mulheres no Islã não é religioso, mas sim de uma religião usada por uma sociedade patriarcal e, portanto, a militância islâmica/feminismo pode realmente permitir que as mulheres desenvolvam um relacionamento moderno com o Islã e abram brechas na ordem patriarcal existente.

Muitas análises sobre o Islã ou sobre a religião são seletivas, não contam toda a história, não fornecem o contexto das atitudes religiosas, eventos e ações, ou então falham em conseguir abarcar toda a diversidade das práticas muçulmanas. Dessa forma, passa despercebido, por exemplo, que a religião tende a ser mais central no processo de modernização no Oriente e a posição das mulheres é afetada por isso. Nos movimentos feministas do ocidente (secular) tende-se a rejeitar a religião, por ela ser identificada com a subordinação e o confinamento das mulheres à esfera privada e doméstica. Já nas sociedades não ocidentais (não especificamente seculares), a religião pode se tornar o lugar e meio para a articulação de movimentos feministas. Fora do Ocidente, o processo de diferenciação entre público e privado tem sido muitas vezes menos rígido. Igualmente, a modernização tem sido um desenvolvimento tanto religioso como secular. Isso significa que a religião não foi "privatizada" ou "domesticada" como no Ocidente e, por conseguinte, as mulheres não tiveram que escolher entre religião (tradicional) e a entrada na vida pública. De antemão, a religião pode servir como mediadora entre o privado e o público de maneiras criativas (Linda WOODHEAD, 2002: 401).

Não importa qual resposta elas possam optar, as mulheres religiosas que estão na vanguarda, reinterpretando o Islã no século XXI, estão trabalhando duro em dois fronts. Na frente interna à religião, na comunidade e na vida privada (não reconhecimento de sua liderança, choque com pais, maridos, violência doméstica), quanto na frente pública e em suas relações com movimentos secularistas, mesmo de mulheres (que determinam como devem se vestir, onde a religião deve ficar etc.). As muçulmanas reconhecem e alertam para uma longa predominância histórica de homens interpretando os textos e as leis do Islã, mas elas começam a criar ferramentas dentro dos espaços para as vozes femini- 
nas e para a participação das mulheres. O Islã, elas insistem, não é um bloco fechado, muito menos é interpretado em todos os contextos da mesma maneira. Ao contrário, por sua própria definição e apresentação do Alcorão, o Islã é um processo, um modo de tornar-se que nunca é finalizado (Amira El-Azhary SONBOL; Hibba ABUGIDEIRI, 2001).

Entretanto, uma visão monolítica do Islã ainda domina discursos populares e acadêmicos. É comum se escutar declarações começando com "o Islã é", "o Alcorão diz", ou de acordo com a "lei islâmica" ou a sharia. ${ }^{4}$ Muito raramente aqueles que falam o que se deve fazer em nome do Islã admitem que a sua opinião é apenas mais uma interpretação entre muitas outras. Os textos sagrados e as leis deles derivadas são questões de interpretação humana. Além disso, aqueles que falam do Islã, ou na verdade, da religião em relação ao Islã, deixam de fazer uma distinção comum quando se fala de religião em outros contextos, ou seja, entre a fé (e seus valores e princípios) e a religião organizada (instituições, leis e práticas). O resultado são as "retóricas generalizadas de qualquer um que glorifica a fé sem reconhecer os horrores e os abusos cometidos em seu nome ou condená-la por equipará-la com aqueles abusos" (Ziba MIR-HOSSEINI, 2006: 632). Claro, fé religiosa e religião organizada estão ligados, mas elas não são a mesma coisa.

É muito comum pesquisadores fazerem análises sobre as religiões e o patriarcado, relatando que as religiões têm uma visão patriarcal na relação entre os gêneros. Apontam que, em comparação com outras

4 "Leis islâmicas" (sharia) estão entre aspas, por conta do debate que já existe, nas escolas feministas islâmicas, questionando a existência de tal coisa como leis islâmicas. Estudiosos muçulmanos e outros afirmam que a sharia é divina. Entretanto, ela é sempre sujeita a fiqh, interpretações jurídicas diretas e extrapolação para casos semelhantes, sendo, portanto, humana e falível. Textos de figh, que são patriarcais em espírito e forma, são com frequência invocados por estudiosos e líderes muçulmanos (homens) como a própria expressão da lei de Deus, como um meio para silenciar e frustrar a busca das muçulmanas por justiça e igualdade, assim, o caráter interpretativo do fiqh. Ziba Mir-Hosseini (2006) assevera que "interpretações patriarcais da sharia podem e devem ser desafiadas a nível do fiqh, que não é nada mais do que a compreensão humana da vontade divina. Em outras palavras, a sharia é o ideal transcendental que personifica a justiça do Islã e o espírito das revelações islâmicas. Este ideal transcendental, que condena todas as relações de exploração e dominação, serve de base para a crítica das mulheres muçulmanas das construções patriarcais das relações de gênero, que se encontram não só no vasto corpus de textos jurisprudenciais, mas também nas leis positivas que são requeridas como se fossem enraizadas nos textos sagrados" (2006: 632). 
religiões, a ideia do patriarcado é ainda mais forte no Islã. Refletindo sobre a subordinação das mulheres nos países islâmicos, mantêm a ideia de que o Islã pode ser definido como o pior tipo de religião patriarcal, a que mais oprime as mulheres e legitima a desigualdade (John Louis ESPOSITO, 1999). Entretanto, outras escolas de pensamento relatam que o problema está na forma como o Islã é entendido e praticado no dia a dia, o que indica como o patriarcado usa a religião em seu favor. Cada vez mais se encontram exemplos de recomendações, práticas e exigências toleradas em nome do Islã que, na verdade, são não islâmicas (Margot BADRAN, 1995).

O patriarcado tem sido um tema bastante importante dentro das relações familiares ao longo da história do Islã. Está vivo no contexto sociopolítico dessas comunidades, embora possa assumir formas diferentes. É importante, entretanto, deixar claro que não é a religião ou especificamente o Islã que é patriarcal. Na verdade, a forma como sociedades patriarcais fizeram interpretações dos textos sagrados é que deve ser responsabilizada pelas relações de poder desiguais entre homens e mulheres. Como argumentou Erica Appelros (2005), a religião é uma importante dimensão da vida das mulheres, que se cruza com outras camadas de identidades e desigualdades. Desse modo, é importante perceber como as mulheres dentro de sistemas religiosos (que podem ser patriarcal em vários graus) podem alcançar diferentes níveis de igualdade (Margot BADRAN, 1995). Tanto que, as "injustiças exercidas contra as mulheres muçulmanas, até hoje, são devidas à influência de ideias pré-islâmicas que influenciaram o pensamento religioso e foram assim incorporadas e canonizadas" (Omayma ABDEL-LATIF e Marina OTTAWAY, 2007: 8).

Mais do que pensar se a religião é patriarcal ou não, se o Islã é a mais patriarcal de todas as crenças ou se a mulher muçulmana é a mais oprimida, é importante ter em mente que existe, em todas as religiões, uma relação entre fé e indivíduos que produz diferentes consequências. Muitos muçulmanos têm uma leitura patriarcal do Alcorão, não pelo texto ser misógino em si, mas por conta dos contextos em que estão inseridos. Em outras palavras, Asma Barlas vai afirmar que os textos são sempre lidos a partir de lugares ideológicos e que precisamos estar 
cientes destes para compreendermos como as leituras são feitas. Onde o Alcorão está em foco, uma série de estudos tem mostrado que ele é continuamente contextualizado e recontextualizado à luz da política sexual muçulmana - e de outros temas - e essa política é esmagadoramente centrada no masculino (Asma BARLAS, 2008: 17).

Por viverem dentro dessas religiões "patriarcais", as mulheres religiosas são comumente vistas como mulheres sem agência. E o que seria a agência que elas presumivelmente não possuem? Normalmente, define-se agência como a capacidade das pessoas para fazer escolhas e agir no mundo de maneira satisfatória às suas preferências individuais e com capacidade de autonomia racional (Phyllis MACK, 2003:151). Muitas feministas inicialmente assumiram que as mulheres queriam (ou deveriam querer) libertação e que a ação coletiva das mulheres cresceria para fora de sua opressão comum. No entanto, estudos posteriores feministas desafiaram tais pressupostos, mostrando como as ações das mulheres podem reproduzir a desigualdade de gênero, pondo em causa a estabilidade das identidades de gênero e interesses compartiIhados (Patricia HILL-COLLINS, 1990; Deniz KANDIYOTI, 1988; Chandra MOHANTY, 1991). Agência é igualmente importante para as estudiosas de gênero e religião que se empenham fortemente em dissipar o estereótipo de que as mulheres religiosas são simplesmente "vítimas" do patriarcado (Arthur GREIL; Lynn DAVIDMAN, 2007).

Tanto que muitos estudos sociológicos recentes das mulheres e religião apresentam a crença como fornecedora de um conjunto de habilidades, ferramentas, esquemas, mecanismos e outros recursos para a agência. As mulheres religiosas podem ser agentes ao invés de, simplesmente, serem obrigadas a praticar a fé por instituições religiosas ou doutrinas. Por isso, é importante discutir, pensar e refletir sobre a noção de agência dessas mulheres para além de argumentos polarizados de submissão versus resistência. Sara Salem vai além e sugere que "uma maneira de conciliar a agência com religião é reconceituar o conceito de agência em si" (Sara SALEM, 2013: 3), centrando-se na realidade vivida de mulheres que são religiosas e usando a interseccionalidade como referência (Sara SALEM, 2013: 7).

Dessa forma, agência e autonomia deixariam de ser definidas pela relação com os poderes externos que tentam sufocar o individualismo 
e criar relacionamentos de dependência. Como apontado por Phyllis Mack, o feminismo passou muito tempo discutindo agência, incorporando certas suposições ao conceito como preconcebidas, no caso, a secularização (Phyllis MACK, 2003: 157). Em decorrência disso, cria-se um binário entre o secular e o religioso ou o espiritual. Isso surgiu, em particular, devido às suposições sobre a modernidade e o progresso que afirmam que indivíduos passam de um estado de religiosidade para um estado de laicidade, evocando assim uma progressão linear de tempo. Isso não só cria um binário entre o secular e o espiritual, como também negligencia o fato de que muitos movimentos religiosos são profundamente modernos (Sara SALEM, 2013: 9).

Um número crescente de estudos feministas sobre religião está envolvido em uma discussão mais crítica e diferenciada da agência em relação à devoção religiosa (Saba MAHMOOD, 2005; Phyllis MACK, 2003; Orit AVISHAI, 2008; Sarah BRACKE, 2008; Kelsy BURKE, 2012; Rachel RINALDO, 2014; Tanya ZION-WALDOKS, 2014). Rachel Rinaldo (2014: 829), em seu estudo das ativistas muçulmanas indonésias, sugere que as religiosas recorrem a fontes seculares e religiosas em suas tentativas de ampliar os direitos das mulheres. Ele lança o termo critical pious agency para denotar "a capacidade de engajar-se criticamente e publicamente com textos religiosos", argumentando que, quando as muçulmanas na Indonésia fazem críticas ao discurso sobre o Islã para favorecerem interesses das mulheres, elas demonstram que subjetividades piedosas e feministas podem se cruzar e se sobrepor.

O exemplo ilustra as múltiplas e complexas formas de agência e cumplicidade que desafiam uma compreensão de oposição entre libertação e subordinação (Line Nyhagen PREDELLI; HALSAA, Beatrice, 2016). Rachel Rinaldo (2014) e Tanya Zion-Waldoks (2015) ainda ressaltam que as subjetividades religiosas femininas são formadas na interação entre discursos, atos de devoção religiosa e resistência às práticas que oferecem suporte à discriminação ancorada no gênero. Os indivíduos são incorporados em contextos sociais em várias camadas, onde as relações sociais cotidianas criam oportunidades e restrições para a agência. Agência pode ser habilitada ou restringida pelos Estados-nações, organizações e instituições, regras e regulamentos, comunidades, grupos, 
famílias e outros. Mas a agência nunca é puramente individual, ela é sempre produzida em relação aos outros (Michal PAGIS, 2013; Tanya ZION-WALDOKS, 2014).

\section{2 "FEMINISMOS"}

Antes de avançar na análise do que as muçulmanas estão fazendo e como estão desenvolvendo o seu feminismo, é importante explicar pontualmente as ondas de desenvolvimento do feminismo e sua pluralidade como movimento. A história do feminismo pode ser dividida em três ondas: a primeira onda feminista se deu no fim do século XIX e início do século XX; a segunda onda foi na década de 1960 e 1970; e a terceira onda se estende desde a década de 1990 até o presente (Maggie HUMM, 1990; Rebecca WALKER, 1992). A primeira onda se refere principalmente ao movimento pelo sufrágio universal, as mulheres preocupadas com a emancipação. A segunda onda, em contraste com a primeira, traz inúmeros relatos de opressões que antes não eram nomeadas. Ao debater e encontrar definições acerca daquilo que as afligia, elas saíam do isolamento e adquiriam poder. A terceira onda está mais disposta a acomodar a diversidade e a mudança. Hoje, as feministas estão particularmente ansiosas em entender as maneiras pelas quais gênero e outros tipos de opressão humana criam e mantêm umas às outras (Rosemarie TONG, 2009).

A primeira onda surgiu no contexto da sociedade industrial e da política liberal, mas está ligada ao movimento liberal pelos direitos das mulheres como no feminismo socialista do final do século XIX e início do século XX nos Estados Unidos e na Europa. Preocupada com o acesso à igualdade de oportunidades, foi caracterizada pela forte crítica às religiões institucionalizadas, que foram acusadas de promover a submissão das mulheres tanto num nível prático como no nível simbólico. Nesse contexto, o feminismo histórico é principalmente anticlerical e rejeita a tradição religiosa como sendo parte da estrutura dominante (Linda WOODHEAD, 2001: 68-69). Por sua vez, movimentos religiosos pelos direitos das mulheres também emergiam nos contextos religiosos. Dentro do cristianismo, surgiu a Société des féministes chrétiennes 
(católica) e o Mouvement Jeunes Femmes (protestante), na França, que estão na raiz da teologia feminista (Teresa FORCADES, 2015; Elizabeth Cady STANTON, 1898).

Na segunda onda, em sociedades ocidentais do pós-guerra, percebe-se um feminismo intimamente ligado às vozes radicais das mulheres e ao direito à diferença. As feministas agora enxergavam as desigualdades culturais e políticas como inextricavelmente ligadas. Tanto que encorajaram outras mulheres a entender as facetas de suas vidas pessoais, tão profundamente politizadas e a manifestá-las como estruturas de poder sexistas. A pensadora crítica feminista Carol Hanisch lançou vários protestos durante o auge do feminismo radical. Foi ela quem criou a frase "o pessoal é político", em 1969, slogan da segunda onda do feminismo. Durante as décadas de 1980 a 1990, ainda ocorreu o início da participação de mulheres de cor e do "Terceiro Mundo" (Rosalyn BAXANDALL e Linda GORDON, 2005: 414).

Em conexão com a segunda onda, houve um interesse crescente das formas de religiosidade que subverteram a hierarquia entre os gêneros ou que excluíam os homens como alguns movimentos da New Age, crenças ancoradas na Deusa da Terra, teorias fundamentadas em formulários do matriarcado e em um laço privilegiado entre mulheres e natureza. Isso não tem necessariamente a ver com a negação da religião, mas sim com o reconhecimento do valor adequado das formas de religiosidade, aquelas especialmente femininas (Linda WOODHEAD, 2001: 79) e dentro de religiões tradicionais (Valerie SAIVING, 1979). Textos sagrados começaram a se tornar objeto de uma releitura crítica. A ministra protestante Brackenbury Crook (1964), por exemplo, ofereceu uma revisão feminista da teologia e da Bíblia, enquanto a teóloga católica Elisabeth Schüssler Fiorenza (1983), uma das fundadoras do Journal of Feminist Studies in Religion, usou uma perspectiva feminista de cunho político e hermenêutico em sua releitura das Escrituras.

Desafiando todas as versões do feminismo que o precederam, na terceira onda, o pensamento feminista aumentou na sua diversidade. A partir da percepção da pluralidade das experiências das mulheres começa a se defender um feminismo diverso, conectado com as histórias que envolvem a vida real de todas as mulheres, não só as brancas. Nesse movimento 
por inclusão, as mulheres de cor foram aquelas que mais levantaram a queixa do silenciamento e, principalmente, criticaram serem inseridas em um universo que elas não escolheram e que não reconhecem (pautas das feministas hegemônicas brancas). Elas vão defender um feminismo não imperialista, que abra espaço real para as suas articulações, interpretações, reflexões e teorias, abandonando reinvindicações universais das mulheres pelo simples fato dessa não ser a realidade de todas elas (Maria LUGONES; Elizabeth SPELMAN, 1983: 573-76).

É difícil trazer uma definição precisa do que é feminismo, nesse novo contexto, pois o termo traduz todo um processo que tem origem no passado, que se constrói no presente e não tem um ponto de chegada. Como todo processo de transformação, contém contradições, recuos, avanços e uma pluralidade de perspectivas, nem sempre convergentes. De uma maneira geral, se poderia definir o feminismo como o movimento social que reivindica a melhoria das condições de vida das mulheres e, para isso, almeja eliminar as desvantagens em relação ao status alcançado pelos homens ao longo da História. Ou talvez, seria melhor dizer feminismos, uma vez que a pluralidade de abordagens é uma das características que esse movimento busca respeitar (Mariana LUCENA, 2012; Luís Felipe MIGUEL e Flávia BIROLI, 2014).

Em cada localidade, através do tempo, conectado com a realidade e necessidades das diferentes mulheres surgem movimentos, muitas vezes mais diversificados do que unidos. Pontuando apenas as ideologias feministas, particular ao movimento ocidental, vai-se encontrar: as feministas liberais, radicais, culturais, marxista-socialistas, anarquistas, ecológicas, pós-coloniais, psicanalíticas, para citar só algumas (Rosemarie TONG, 2009). Independentemente do rótulo, um consenso parece gradualmente se acumular entre formuladores de políticas, redes de apoio de mulheres e indivíduos - não apenas entre os círculos das pensadoras feministas - a violência ancorada no gênero e tentativas de subordinação para "dominar" as mulheres existe. Está em todas as sociedades, em todo o ciclo da vida e através de todas as clivagens socioeconômicas e culturais (Aisha GILL e Gulshun REHMAN, 2004: 75).

Todavia, de maneira oposta à homogeneização e unificação das "muIheres", chega-se, nos anos de 1960, ao feminismo "pós-colonial” (África, 
Caribe, América Latina e sudeste da Ásia), para exaltar as diferentes experiências que marcam a vida das mulheres. A qualidade de vida nessas localidades é pior do que a das mulheres em nações mais desenvolvidas. Essas feministas desafiam as mulheres em países desenvolvidos a reconhecer que muitos dos seus privilégios são conquistados em detrimento do bem-estar das mulheres nos países em desenvolvimento (Rosemarie TONG, 2009: 8). Algumas feministas pós-coloniais, como Chandra Mohanty, desaprovam o feminismo ocidental, classificando-o como etnocêntrico. Ela ainda localiza na escola feminista ocidental recente uma peça da colonização discursiva, vinculando-a ao imperialismo. Para a pensadora, a produção das mulheres do terceiro mundo é enquadrada como um "sujeito monolítico singular, um grupo sempre já constituído, que tem sido rotulado como impotente, exploradas, assediadas sexualmente e assim por diante" (Chandra MOHANTY, 1984: 26).

O feminismo das ativistas muçulmanas de gênero pode ser enquadrado no amplo contexto do feminismo do "Terceiro Mundo" e do feminismo cultural (Dunya MAUMOON, 1999: 275). Ativistas islâmicas tomam a posição em que as normas e valores do feminismo ocidental não se aplicam a elas no total. Feminismo como um fenômeno que envolve questões dos direitos das mulheres, libertação das mulheres e igualdade de gênero. Além de ser parte integrante dos direitos de libertação e igualdade de todos, foi construído e moldado simultaneamente por muçulmanos e outros no Oriente (países da África e Ásia) e pelos ocidentais no final do século XIX e XX. A História atesta que o feminismo é criação dos orientais e ocidentais, dos muçulmanos e daqueles de outras religiões, dos colonizados e colonizadores e das mulheres de diferentes raças e etnias. Aqueles que afirmam que o feminismo é western e "branco" não conhecem sua história e perpetuam a circulação dos mitos (Margot BADRAN, 2008: 25).

O conceito de "interseccionalidade" 5 é fruto do movimento feminista negro e surge a partir da percepção de que a opressão não é um

5 O termo em si foi desenvolvido por Kimberlé Crenshaw (1989), quando ela discutia questões relacionadas aos empregos das mulheres negras no Estados Unidos, para suprir as diversas faIhas - judiciais, teóricas e políticas - - dentro do feminismo e do movimento negro que não dão conta de explicar por si só as situações em que a discriminação não é só ao gênero ou à raça, mas à combinação destas duas categorias discriminatórias (Kimberlé CRENSHAW, 1989: 11). 
processo singular ou uma relação política binária, mas é melhor compreendida como um sistema múltiplo que se entrelaça e converge. 0 conceito deriva de críticas feministas às alegações de que a opressão feminina pode ser capturada apenas por uma análise de gênero (Anna CARASTATHIS, 2014: 304). Dessa forma:

...a interseccionalidade remete a uma teoria transdisciplinar que visa apreender a complexidade das identidades e das desigualdades sociais por intermédio de um enfoque integrado. Ela refuta o enclausuramento e a hierarquização dos grandes eixos da diferenciação social que são as categorias de sexo/gênero, classe, raça, etnicidade, idade, deficiência e orientação sexual. O enfoque interseccional vai além do simples reconhecimento da multiplicidade dos sistemas de opressão que opera a partir dessas categorias e postula sua interação na produção e na reprodução das desigualdades sociais (Sirma BILGE, 2009: 70).

Abordagens interseccionais à desigualdade desafiam a noção de que gênero é sempre de primordial importância para a vida das mulheres e introduzem a noção de que as mulheres experimentam diferentes formas de desigualdade, dependendo de seu posicionamento em relação a suas múltiplas identidades (ver, por exemplo, Kimberlé CRENSHAW, 1997; Nira YUVAL-DAVIS, 2006). Helma Lutz inclui eixos adicionais chamados de "linhas de diferença", que levam em consideração: gênero; sexualidade; raça/cor de pele; etnia; nação/Estado; classe; cultura; capacidade; idade; sedentarismo; riqueza; Norte-Sul; religião; estágio de desenvolvimento social. Helma Lutz, no entanto, vê essa lista como "de nenhuma maneira completa; outras categorias têm que ser adicionadas ou redefinidas" (Helma LUTZ, 2002:13). É ancorada nessas várias intersecções que Frédérique Ast e Riem Spielhaus (2012: 437) argumentam que a discriminação das muçulmanas que usam o véu não pode ser fundamentada exclusivamente na religião. Eles refletem uma abordagem que "não leva em conta as múltiplas identidades das vítimas como mulheres e crentes e, portanto, a interseção de gênero e religião". Para Sara Salem (2013: 11), só uma abordagem interseccional de mulheres muçulmanas e da religiosidade permite que a experiência religiosa da mulher muçulmana seja parte da narrativa de suas próprias histórias. 


\section{FEMINISMO ISLÂMICO}

\subsection{Feminismo islâmico versus feminismo secular}

O feminismo no Oriente Médio tem mais de um século de idade, desde lá, se formaram dois grandes paradigmas feministas referidos como "feminismo secular" e "feminismo islâmico". O momento fundacional do feminismo secular pode ser atribuído ao final do século XIX, enquanto o surgimento do feminismo islâmico tornou-se evidente no final do século XX. Esses feminismo/s apareceram principalmente em sociedades de maioria muçulmana com religióes plurais e/ou de várias etnias. Feminismo secular baseia-se e é constituído por múltiplos discursos, incluindo nacionalista secular, modernista islâmico, direitos humanos/humanitário e democrático. O feminismo islâmico é expresso em um único fundamento religioso embasado no discurso do Alcorão como seu texto central (Margot BADRAN, 2005).

A ascensão do feminismo secular coincidiu com dois fenômenos: a disseminação de novas tecnologias da informação com a chegada da imprensa; e a propagação da alfabetização entre as mulheres (dos estratos médios e superiores). Juntos, esses fenômenos deram origem a uma nova escrita e leitura pública de mulheres. Mulheres transcenderam os limites da comunidade religiosa, com elas se juntaram esforços na elaboração de um discurso feminista articulado nos escritos novos e recentes redes de mulheres (Thomas COOKE, 2008; Nikki KEDDIE; Beth BARON, 1992).

O feminismo islâmico emergiu na década de 1990, em um momento pós-colonial atrasado e num tempo de profundo descontentamento sobre a incapacidade dos países do Oriente Médio para entregar a democracia e promover a prosperidade econômica. Mulheres, ambas as secularistas e religiosas, cresceram cada vez mais preocupadas com a imposição e a propagação de uma leitura conservadora do Islã pelos movimentos islâmicos, encontrando a necessidade de responder em uma progressiva voz islâmica. Os termos tanto feminismo secular como feminismo islâmico são duramente criticados até mesmo por quem participa dos movimentos. Não se pode pensar os dois movimentos como visões opostas que nunca dialogam, na verdade eles vêm desenvolvendo conversas construtivas e unindo forças. Examinar experiências concretas 
indica como as mulheres muçulmanas como feministas empregam os vários discursos e possuem múltiplas identidades (Margot BADRAN, 2009). Comparando os dois feminismos no Oriente Médio, pode-se observar que o feminismo secular compartilha com o nacionalismo secular uma narrativa progressiva de gênero e a nação, embora o feminismo secular desenvolveu as ideias de gênero mais plenamente e exigiu que as palavras fossem traduzidas em ações no presente, não em algum futuro indefinido. Incipiente, o feminismo islâmico, por sua vez, se afastou da narrativa de islamistas conservadores, oferecendo em seu lugar um discurso islâmico progressivo. Se o feminismo islâmico veio à tona quando o islamismo estava ascendente no Oriente Médio, essa mesma narrativa surgiu a partir do solo fértil de uma tradição bem estabelecida, o feminismo secular (Margot BADRAN, 2009).

É importante considerar o feminismo secular e o feminismo islâmico como dois fenômenos nomeados. Enquanto eles principalmente são vistos como diferentes e, muitas vezes, em tensão um com o outro, eles raramente são vistos como fluindo dentro e fora do outro. Na visão de Margo Badran (2005), é importante defender que o feminismo secular é islâmico e o feminismo islâmico é secular. Existem vários pontos de onde os feminismos irradiam para fora. O Ocidente não é a casa patrimonial dos feminismos da qual derivam todos os feminismos e contra os quais eles devem ser medidos. Com efeito, o feminismo do Oriente Médio gerou uma crítica ocidental ao "feminismo imperial" quando as mulheres trouxeram as ideias e modos de ativismo de seus próprios feminismos secular/nacional para a tabela do feminismo internacional (Ocidental dominado) durante o século XX (Margot BADRAN, 2005).

Diante disso, é importante ter em mente que o feminismo é uma planta que cresce somente em seu próprio solo. Não diferente disso, o feminismo islâmico começou a surgir simultaneamente uma década e meia atrás em antigas sociedades islâmicas em partes da África e Ásia e em comunidades mais recentes na Europa e América do Norte. No Irã, pós-Khomeini, por exemplo, as mulheres muçulmanas criaram uma nova revista, a Zanan. ${ }^{6}$ Como cidadãs de uma República Islâmica, cha-

Zanan foi uma revista iraniana (1992) editada por Shahla Sherket, como parte desse esforço crescente pela presença de mulheres no jornalismo. Zanan é uma revista literária e cultural com uma agenda explicitamente feminista e com publicações regulares sobre o divórcio, violência sexual e a guarda dos filhos (WLUML, 2002: 25). 
maram a atenção, em nome do Islã, para os direitos das mulheres que estavam sendo infringidos. Na África do Sul pós-apartheid, mulheres e homens, em uma das batalhas mais ferozes da História pela dignidade humana, focaram sua atenção nas questões de justiça, especialmente da justiça de gênero. Dentro de sua própria comunidade muçulmana, lutaram pelo acesso ao espaço comunitário/mesquita para todos (Margot BADRAN, 2006).

O feminismo islâmico é um fenômeno interislâmico, produzido pelas muçulmanas em várias localidades ao redor do globo. Não há qualquer linha Ocidente/Oriente que o localize espacialmente. O feminismo islâmico, como o Islã de hoje, está no Ocidente como está no Oriente. críticos muçulmanos alegam que o "Ocidente" tem imposto o feminismo - primeiramente secular e agora islâmico - sobre as muçulmanas em detrimento do Islã e da sociedade. As defensoras muçulmanas, por sua vez, asseguram que feminismo islâmico promove a justiça social dentro da ummah, enquanto também contribui para a criação de uma sociedade mais plural e justa, onde todos insan (seres humanos) serão tratados como iguais independentemente da sua etnia, religião ou gênero (Margot BADRAN, 2006).

O feminismo islâmico já está sendo produzido em diversos locais ao redor do mundo, em países com maiorias muçulmanas ou com comunidades minoritárias bem estabelecidas. O feminismo islâmico também está crescendo na diáspora muçulmana e nas comunidades de convertidas no Ocidente. Também está crescentemente circulando no ciberespaço. Transcende e tenta destruir os velhos binários que foram construídos, incluindo polaridades entre "religioso" e "secular" e entre "Oriente" e "Ocidente". Fecha as lacunas e demonstra comuns preocupações e objetivos, começando com a afirmação básica da igualdade e justiça social. Sugestões ou denúncias de um suposto "confronto" entre "feminismo secular" e "feminismo religioso" podem também ser o produto da falta de conhecimento histórico ou, como em muitos casos, uma tentativa politicamente motivada para dificultar a solidariedade entre as mulheres (Margot BADRAN, 2002). 


\subsection{Conceito do feminismo islâmico}

O que há por trás de um nome? O que significa? É real? Feminismo islâmico é um discurso e uma prática feminista articulada dentro do paradigma islâmico. Deriva sua compreensão e mandato do Alcorão. Busca direitos e justiça para as mulheres e para homens, na totalidade da sua existência, explicitando a ideia da igualdade de gênero como parte integrante e parcela da noção de igualdade de todos (seres humanos). Rejeita a noção de uma dicotomia público/privado conceptualizando uma ummah holística, em que os ideais do Alcorão são operativos em todo o espaço. O feminismo islâmico é tanto altamente contestado como firmemente abraçado. Tem havido muito mal-entendido e deturpação sobre o seu significado. Dessa forma, se esclarecerão alguns deles (Margot BADRAN, 2014).

O feminismo islâmico assumiu a dupla tarefa de expor e erradicar ideias e práticas patriarcais camufladas como "naturalizadas" islâmicas e perpetuadas sob esse pretexto - e para se recuperar a ideia núcleo do Islã da igualdade de gênero (indivisível da igualdade humana). Com o surgimento e desenvolvimento desse feminismo islâmico, incorreram inimigos de dentro e de fora da comunidade muçulmana: 1) a partir de dentro: os homens que temem a perda do privilégio patriarcal e mulheres que temem a perda de proteção patriarcal e 2) da parte de fora: daqueles cujos prazeres são encontrados manchando o Islã como irremediavelmente antimulheres (Margot BADRAN, 2006).

O feminismo islâmico é um fenômeno global. Não é um produto do Ocidente ou do Oriente. Na verdade, transcende o Ocidente e o Oriente. O feminismo islâmico já está sendo produzido em diversos locais ao redor do mundo por mulheres dentro de seus próprios países, quer provenientes de países com maiorias muçulmanas, quer de comunidades minoritárias com idade estabelecida. O feminismo islâmico também está crescendo na diáspora muçulmana e nas convertidas comunidades no Ocidente. O feminismo islâmico está circulando com o aumento frequente no ciberespaço. Transcende e destrói os velhos binários que foram construídos. Estes incluíram polaridades entre "religioso" e "secular" e entre "Oriente" e "Ocidente". Muitos reconhecem o discurso feminista islâmico, como criação ou reconfirmação das polaridades. 
Entretanto, Margot Badran argumenta que o discurso feminista islâmico faz precisamente o contrário; ele fecha as lacunas e demonstra comuns preocupações e objetivos, começando com a afirmação básica da igualdade e justiça social. Sugestões ou denúncias de um suposto "confronto" entre "feminismo secular" e "feminismo religioso" podem também ser o produto da falta de conhecimento histórico ou, como em muitos casos, uma tentativa politicamente motivada a dificultar mais amplas solidariedades entre as mulheres (Margot BADRAN, 2014).

\subsection{Bases teóricas e analíticas}

Que o feminismo islâmico faz parte dos feminismos já se sabe. Agora, falta entender se existe alguma contradição em ser feminista e muçulmana. Em que bases o discurso feminista islâmico está sendo constituído? Quais são as suas metodologias? E qual a sua hermenêutica? Primeiramente, não há contradição alguma entre ser feminista e ser muçulmana. Percebe-se que o feminismo, quando considerado uma tomada de consciência sobre os constrangimentos das mulheres, por causa do gênero, rejeita tais limitações e se esforça em construir e implementar uma forma mais equitativa de um sistema de gênero. O argumento básico do feminismo islâmico é que o Alcorão afirma o princípio da igualdade de todos os seres humanos, mas que a prática da igualdade entre mulheres e homens (e outras categorias de pessoas) tem sido impedida ou subvertida por ideias patriarcais (ideologia) e práticas (Margot BADRAN, 2002).

As feministas islâmicas exegetas se conectam à ideia de igualdade de toda a humanidade a partir da ideia do tawhid, ou seja, da unicidade de Deus. Nenhum ser humano pode participar da unicidade deste. Nenhum ser humano pode ou deve agir como um deus ou se apropriar do que é devido somente a Deus, que é único, para os muçulmanos, e, portanto, não tem gênero. Ta'a, ou obediência, é devida a "ele" somente. Dentro do universo islâmico patriarcal, existe a crença de que as mulheres devem obediência aos homens. Essa obediência tem sido fortemente construída e imposta rigorosamente pelo masculino. Se as interações sociais são ancoradas na tawhid, então, por necessidade, 
devem conduzir a relações igualitárias, desde que a hierarquia e a dominância negue a entrega a Deus, o objetivo de todos os muçulmanos que desejam ser fiel ao princípio de tawhid (WADUD, 1999: 33-34).

A hermenêutica feminista islâmica está ancorada em três abordagens: 1) revisitar versículos do Alcorão para corrigir falsas histórias de comum circulação, como os contos de criação e eventos no jardim do Éden que têm escorado reivindicações de superioridade masculina; 2) citar versículos que inequivocamente enunciam a igualdade entre mulheres e homens; 3) desconstruir versículos atentos à diferença de homem e mulher que têm sido comumente interpretados de maneiras a justificar a dominação masculina. O feminismo islâmico serve às pessoas em suas vidas individuais e também pode ser uma força para melhorar o Estado e a sociedade. O feminismo islâmico ajuda as muçulmanas a desmembrar o patriarcado da religião. Concede-Ihes maneiras islâmicas da compreensão de seu próprio potencial, oportunidade social e igualdade de gênero (Margot BADRAN, 2002).

Assim, uma prioridade do feminismo islâmico é ir direto ao texto sagrado fundamental do Islã, o Alcorão, em um esforço para recuperar sua mensagem igualitária. Algumas mulheres focam exclusivamente no Alcorão (Amina Wadud, Rifaat Hassan, Saudi Arabian, Fatima Naseef); outras aplicam suas releituras do Alcorão e a sua análise das diversas formulações da sharia (Aziza Al-Hibri e Shaheen Sardar Ali); enquanto outras se concentram em reexaminar o hadith ${ }^{7}$ (Fatema Mernissi, Turkish Hidayet Tuksal). As metodologias básicas desse feminismo islâmico são as metodologias islâmicas clássicas de ijtihad ${ }^{8}$ (investigação independentemente das fontes religiosas) e tafsir $^{9}$ (interpretação do Alcorão). Com essas metodologias, são usados os métodos e ferramentas da linguística, história, crítica literária, sociologia, antropologia etc. (Margot BADRAN, 2009).

Hadith, plural Ahadith: são as tradições reportadas e autenticadas que o profeta disse, fez ou aprovou (Tariq RAMADAN, 2004: 254).

8 ljtihad: literalmente "esforço", tornou-se um termo técnico que significa o esforço realizado por um jurista, ou para decidir/extrair uma lei por meio de não explícitas fontes bíblicas ou para formular um parecer jurídico específico na ausência de textos referência (Tariq RAMADAN, 2004: 254).

9 Tafsir é a ciências da exegese (Tariq RAMADAN, 2004: 57). 
Uma grande quantidade de escritos de mulheres muçulmanas começou a aparecer nas últimas décadas do século $X X$, discutindo questões sobre mulheres e gênero dentro de uma perspectiva islâmica. Fatema Mernissi, socióloga marroquina, publicou Women and Islam: An Historical and Theological Inquiry (1991), expondo a fraudulência de hadiths misóginos (ditos e atos atribuídos ao profeta Muhammad). Ela claramente culpa os primeiros estudiosos muçulmanos por induzirem as pessoas ao erro e manipularem os textos sagrados de acordo com seus interesses (Fatema MERNISSI, 1995: 119). Leila Ahmed, primeira professora de estudos femininos de religião da Universidade de Harvard, publicou em 1992 o seu livro Women and Gender in Islam, onde desafiou suposições sobre as mulheres na história do Islã e informou décadas de discussões em torno do complexo debate envolvendo o véu islâmico.

Outro importante nome, Amina Wadud tornou-se uma muçulmana aos 20 anos de idade e publicou Qur'an and Woman: Reading the Sacred Text from a Woman's Perspective (1999), elucidando as mensagens de justiça social e igualdade de gênero encontradas na escritura sagrada. Também pregou (imaan) na oração de sexta-feira - um papel tradicionalmente tomado pelos homens - em uma mesquita na cidade do Cabo, em 1994. Continua a liderar as orações em congregações mistas em todo o mundo (cf. www.islamandfeminism.org/amina-wadud.tml). Em 2006, Amina Wadud publicou outro trabalho: Inside the Gender Jihad: Women's Reform in Islam, elaborando uma hermenêutica sobre mulheres e gênero e dando grande atenção ao significado da jihad de gênero como uma maneira de captar o projeto do feminismo islâmico (Anitta KYNSILEHTO, 2008). A jihad seria o movimento para a inclusão das mulheres em todos os aspectos da prática muçulmana, construção política e na liderança política e religiosa (Amina WADUD, 2006).

Em 2002, Asma Barlas publicou Believing Women in Islam: Un-reading Patriarchal Interpretations of the Qur'an, desafiando leituras opressivas do Alcorão e oferecendo uma leitura que confirma que as muçulmanas podem lutar por igualdade no âmbito dos ensinamentos do Alcorão, ultrapassando o controle sobre o conhecimento religioso por "especialistas" (Asma BARLAS, 2002). Nessa época, o feminismo islâmico já estava bem estabelecido, entretanto, identificações com o conceito são complexas, 
apesar de as escritoras na Zanan publicamente se identificarem com o feminismo. Outras, reverenciadas como as criadoras dos textos seminais do feminismo islâmico, rejeitaram firmemente o rótulo. Ao longo do tempo, no entanto, algumas, como Amina Wadud, se tornaram mais tolerantes, mesmo que ela não se rotule como uma feminista islâmica. No entanto, Asma Barlas continua a se incomodar quando é referida como uma feminista islâmica, mesmo quando o termo é usado puramente para fins analíticos. Várias se opõem à classificação de feministas por razões políticas e profissionais. Algumas ainda acham que estão sendo reduzidas a uma única identidade (Anitta KYNSILEHTO, 2008).

\section{CONSIDERAÇÕES FINAIS}

Não há um feminismo islâmico homogêneo. Formaram-se diferentes metodologias e abordagens; a unidade é identificada sobre os objetivos visados pelos diferentes tipos de feminismos islâmicos. No entanto, a proliferação dessas várias formas funciona como um fator positivo, revelador da convergência dos projetos ocidental modernista e islâmico reformista. Estimula a elaboração e a promoção de alguns sistemas teóricos para construir alternativas viáveis capazes de superar a dicotomia preconcebida do Islã na atualidade (Alina Isac ALAK, 2015). Quando chamamos algo de "feminismo islâmico", pode-se fechar a possibilidade de vê-lo como qualquer coisa e esse fechamento pode ser problemático. Entretanto, quando ignoramos a escolha das pessoas de nomearem seu trabalho, suas lutas, suas teorias ou sua ação, fazemos necessariamente alguma violência epistêmica contra elas. Além disso, a autonomia para se definir parece um importante princípio para defender as definições próprias, independentemente honestas, como realmente são. Afinal de contas, nomear outras pessoas, ou o mundo, em nome de outras pessoas, não é tão honesto (Asma BARLAS, 2008).

Em relação a esse aporte teórico discutido, alguns pontos precisam ser ressaltados. Primeiramente, a religião continua a ser percebida como uma fonte fixa de unidade comunal e identidade geradora de conflito na política internacional europeia. Os dois países escolhidos pelo trabalho, durante sua construção de Estado, desenharam relações diferentes em 
relação ao religioso. Enquanto a lei de 1905 estabeleceu, na França, a separação do Estado da igreja, na Inglaterra ocorreu o reconhecimento de uma igreja formalmente. No entanto, a percepção francesa em relação à religião acredita que o Estado deve ignorá-la. Já na Inglaterra, mesmo com uma igreja estabelecida, ao longo dos anos, retiraram-se os privilégios da igreja abrindo diálogo com os outros credos. A chegada do Islã nesse ambiente secular gera debates envolvendo a religião e a política que, presumidamente, se achava que tinham sido resolvidos há muito tempo, mas que são contestados mais uma vez. Os muçulmanos se apresentam e demandam reconhecimento como muçulmanos, não só como indivíduos. A forma como cada um dos dois Estados vai acomodar essa população e dialogar com ela também será distinto.

A sociedade britânica não tem grandes dificuldades em reconhecer a identidade de grupo, incluindo a religiosa. Dessa forma, os muçulmanos não precisam se identificar com a cultura dominante. Na França, por sua vez, as origens culturais devem ser apagadas e substituídas pela da nação e as particularidades são reservadas para a esfera do privado. 0 liberalismo francês laico faz uma separação entre o público e o privado para garantir que os indivíduos possam ter igual status de cidadão. $\mathrm{Na}$ Inglaterra, as diferenças são reconhecidas e o multiculturalismo é a política que foi desenvolvida para garantir as proteções individuais, que vai além dos princípios básicos, e são garantidos a todos no Estado liberal-democrático. Os muçulmanos, assim como o gay e como a muIher, passam a demandar que sua identidade não seja apenas tolerada no privado, ela deve ser visivelmente pública.

A religião adquire uma maior relevância no contexto pós 11 de Setembro. A "ameaça muçulmana" passa a ser entendida como a antítese do ocidente. O secular, o moderno, o liberal, estão todos correndo perigo. E as mulheres muçulmanas, portando o véu (hijab, chador, burqa, nicab etc.), são visivelmente religiosas e passam a ser o grande símbolo dessa atemorização. Os antagonismos que envolvem o Islã como a antítese do Ocidente permanecem e reforçam estereótipos envolvendo a religião e como ela é atrasada, misógina, patriarcal. As muçulmanas continuam percebidas como seres sem voz, sem agência, sem poder. Porém, não existe relação hierárquica dentro da religião islâmica, desde 
certa perspectiva, e os ensinamentos mostram que Deus vê a todos como iguais.

Entretanto, o que vem acontecendo, durante todos esses anos de prática e fé, como também ocorreu em vários locais com diversas religiões é a manipulação do que foi escrito nos textos religiosos por sociedades patriarcais que insistem em colocar a mulher como um ser sem valor, e muitas vezes, essa fala - de submissão - é acompanhada pela justificativa divina. Dito isso, é importante destacar que, mesmo existindo a possibilidade de interpretar e aplicar o texto islâmico a partir de uma perspectiva de justiça de gênero, defendido pelas feministas religiosas e islâmicas, ao longo desses anos, existe uma cultura muçulmana patriarcal que vem reproduzindo e reforçando uma leitura patriarcal dos ensinamentos.

Todavia, os valores retrógrados comumente associados aos contextos religiosos vêm sendo desafiados pelas próprias feministas da religião e no enquadramento do Islã são desafiados pelas feministas islâmicas. As muçulmanas, em todos os locais, têm contribuído para a redefinição do feminismo construindo várias epistemologias feministas e articulando conceitos alternativos das mulheres que incluem autênticas autorrepresentações de grupos heterogêneos de mulheres. Enfatizar as múltiplas identidades das mulheres muçulmanas e o importante papel desempenhado pela pluralidade de contextos específicos em que elas existem, esclarece os complexos e sofisticados aspectos que determinam as análises de gênero no espaço muçulmano. Uma reação estereotipada, a imagem de oprimida que muitas vezes se vislumbra quando alguém escuta a palavra "muçulmana", pode até ser verdadeira, num contexto social e histórico específico, mas nunca pode ser a regra.

Pensar, refletir e imaginar "mulheres muçulmanas" e, especialmente, o lugar da mulher no Islã é observar a mulher muçulmana - sujeito da sua religião - e perguntar a ela, não às escrituras, o que é o islã? O que significa para você a sua fé? Como a sua fé lhe direciona no seu dia a dia? É possível deixar a fé em casa? Questionar a mulher e não a fé e todos os seus ensinamentos e recomendações, o que é viver a religião. Ela, somente a mulher muçulmana, a partir da sua relação direta com o seu credo e ocupando um contexto específico, que pode ser na Ásia, 
Europa, Oriente Médio, América, vai poder responder a essa pergunta, e se espera que essas respostas sejam as mais diversas possíveis.

Como cidadãs da fé, elas têm uma visão religiosa da vida. Dessa forma, não é possível estudá-las sem a dimensão que direciona a sua percepção do mundo. Mesmo religiosas, as muçulmanas são mulheres de ação, ativas nos seios de suas comunidades buscando justiça, inclusive de gênero. Essa realidade, na Europa Ocidental é tão verdadeira que já existem várias plataformas, organizações, coletivos e multiplicidade de vozes muçulmanas chamando a atenção. Suas militâncias e reinvindicações, ora excluídas, ora não percebidas nas funções sociais, passam a ter maior visibilidade e a fazerem ecos. Elas têm buscado espaço, tanto na vida privada quanto na vida pública, as muçulmanas estão cada vez mais articuladas sobre a importância da modelagem do Islã como uma religião da razão, moderação e realização espiritual.

\section{REFERÊNCIAS}

ABDEL-LATIF, Omayma; OTTAWAY, Marina. Women in Islamist Movements: Toward an Islamist Model of Women's Activism. Beirute: Carnegie Endowment for International Peace, 2007.

AHMED, Leila. Women and Gender in Islam. Londres: Yale University Press, 1992.

ALAK, Alina Isac. Islamic Feminism(s): A Very Short Introduction. Bucareste: Analize Journal of Gender and Feminist Studies, v. 18, n. 4, p. 31-39, [s.n], 2015.

APPELROS, Erica. Religion och intersektionalitet. Kvinnovetenskaplig: Tidskrift, v. 2, n. 25, p. 69-80, 2005.

ASHRAF, Saimah. Shattering Illusion: Western conceptions of Muslim women, 1999. Disponível em: < http://www.iupui.edu/ msaiupui/shatter.html>. Acesso 23 abr. 2018.

AST, Frédérique, \& SPIELHAUS, Riem. Tackling double victimization of Muslim women in Europe: The intersectional response. Mediterranean Journal of Human Rights [s.n], n. 16, p. 357-382 [s.n] 2012.

AVISHAI, Orit. "Doing Religion" in a secular world: Women in conservative religions and the question of agency'. Gender \& Society, v. 22, n. 4, p. 409-433, ago. 2008.

BADRAN, Margot. Feminists, Islam, and nation: Gender and the making of modern Egypt. Princeton: Princeton University Press, 1995.

. Islamic feminism: what's in a name? Al-Ahram Weekly Online, n. 569, p. 17-23, jan. 2002. Disponível em: http://weekly.ahram.org.eg/Archive/2002/569/cu1.htm. Acesso 10 jul. 2017.

Mandrágora, v.24. n. 2, 2018, p. 5-38 
. Islamic feminism revisited. Al-Ahram Weekly On-line, n. 781, p. 9-15, fevereiro, 2006. Disponível em: http://weekly.ahram.org.eg/Archive/2006/781/cu4.htm. Acesso 20 dez. 2016.

. Engaging Islamic Feminism. In: Islamic Feminism: Current Perspectives, ed. KYNSILEHTO, Anitta. Tampere: University of Tampere, p. 25-37, 2008.

2009.

. Feminism in Islam: secular and religious convergences. London: Oxford Press,

BARLAS, Asma. 'Believing Women' in Islam: Un-reading Patriarchal Interpretations of the Qur'an. Texas: University of Texas Press, 2002.

. Engaging Islamic Feminism: Provincializing Feminism as a Master Narrative. In: KYNSILHETO, Anitta (Ed.) Islamic Feminist: current perspectives. Finland: Tampere Peace Research Institute Occasional Paper No. 96, 2008.

BAXANDALL, Rosalyn; GORDON, Linda. Second-wave Feminism. In: ed. Hewitt, N. A Companion to American Women's History. Nova Jersey: Blackwell Publishing Ltd, p. 414-432, 2005.

BAYES, Jane H.; TOHIDI, Nayereh. Women redefining modernity and in the globalized context. In: Globalization, Gender and Religion: The Politics of Women's Rights in Catholic and Muslim Contexts. Basingstoke: Palgrave, 2001.

BILGE, Sirma. Théorisations féministes de l'intersectionnalité. Diogène, v. 1, n. 225, p. 70-88 [s.n], 2009.

BRACKE, Sarah. Conjugating the modern/religious, conceptualizing female religious agency. Theory, Culture \& Society, v. 25, n. 6, p. 51-67, nov. 2008.

BURKE, Kelsy C. 'Women's agency in gender-traditional religions: A review of four approaches'. Sociology Compass, v. 6, n. 2, p. 122-133, jan. 2012.

CADY, Linell e FESSENDEN, Tracy. Religion, the Secular, and the Politics of Sexual Difference. Nova York: Columbia University Press, 2013.

CARASTATHIS, Anna. The Concept of Intersectionality in Feminist Theory. Philosophy Compass, v. 9, n. 5, p. 304-314, abr. 2014.

COOKE, Thomas J. Gender Role Beliefs and Family Migration, Population, Space and Place. Wiley Online Library, v. 14, n. 3, p. 163-75, mar. 2008.

CRENSHAW, Kimberlé et al. Critical Race Theory: The Key Writings That Formed the Movement. New York: New Press, 1996.

DHALIWAL, Sukhwant; YUVAL-DAVIS, Nira. Women Against Fundamentalism. Stories of Dissent and Solidarity. London: Lawrence and Wishart, 2014.

ESPOSITO, John Louis. The Islamic Threat: Myth or Reality? Oxford: Oxford University Press, 1999. 
FORCADES, Teresa. La teologia femminista nella storia. Il ruolo delle donne e il diritto all'autodeterminazione femminile. Roma: Nutrimenti, 2015.

GILL, Aisha; REHMAN, Gulshun. Empowerment through activism: responding to domestic violence in the South Asian Community in London. Gender \& Development, v. 12, n. 1, p. 75-82, mai. 2004.

GREIL, Arthur L.; DAVIDMAN, Lynn. Religion and identity. In: eds. BECKFORD, James; DEMERATH III, N. J. The SAGE Handbook of the Sociology of Religion. Londres: Sage, p. 549-565, 2007.

HILL-COLLINS, Patricia. Black Feminist Thought. Knowledge, Consciousness, and the Politics of Empowerment. Boston: Unwin Hyman, 1990.

HUMM, Maggie. The dictionary of feminist theory. Columbus: Ohio State University Press, 1990.

KABBANI, Rana. The Gender Jihad. The Guardian, 22 jan. 1992. Al-Hibri, A. The practice and purpose of Islamic feminism. The Official Student Newspaper, v. 96, n. 25, p. 1-5, abr. 2002.

KANDIYOTI, Deniz. Bargaining with Patriarchy. Gender and Society, v. 2, n. 3, p. 27490, set. 1988.

KEDDIE, Nikki; BARON, Beth. Women in Middle Eastern History: Shifting Boundaries in Sex and Gender. Londres: Yale University Press, 1992.

KYNSILEHTO, Anitta. Islamic Feminism: Current Perspectives. University of Tampere: Juvenes Print, 2008.

LUCENA, Mariana B. N. de. “Os Debates do Movimento Feminista: Do Movimento Sufragista ao Feminismo Multicultural”, $17^{\circ}$. Encontro Nacional da Rede Feminista e Norte e Nordeste de Estudos e Pesquisa sobre a Mulher e Relações de Gênero [s.n], dez. 2012. LUGONES, Maria C.; SPELMAN, Elizabeth V. Have We Got a Theory for You! Feminist Theory, Cultural Imperialism and the Demand for 'the Woman's Voice'. Women's Studies International Forum, v. 6, n. 6, p. 573-81, 1983.

LUTZ, Helma. Intersectional Analysis: A Way Out of Multiple Dilemmas? Artigo apresentado na Conferência da Associação Internacional de Sociologia, em Brisbane, jul. 2002.

MACK, Phyllis. Religion, feminism, and the problem of agency: Reflections on eighteenth-century Quakerism'. Signs, v. 29, n. 1, p. 149-177 [s.n], 2003.

MAHMOOD, Saba. The Politics of Piety. The Islamic Revival and the Feminist Subject. Princeton e Oxford: Princeton University Press, 2005.

MAUMOON, Dunya. Islamism and gender activism: Muslim women's quest for autonomy. Journal of Muslim Minority Affairs, v. 19, n. 2, p. 269-283, mar. 1999.

MERNISSI, Fatema. The Harem Within: Tales of a Moroccan girlhood. Londres: Bantam Books, 1995. 
MIGUEL, Luís Felipe; BIROLI, Flávia. Feminismo e Política: uma introdução. São Paulo: Boitempo, 2014.

MIR-HOSSEINI, Ziba. Muslim Women's Quest for Equality: Between Islamic Law and Feminism. Critical Inquiry, v. 32, n. 4, p. 629-645 [s.n], 2006.

MOHANTY, Chandra. Under Western Eyes: Feminist Scholarship and Colonial Discourses. Humanism and the University I: The Discourse of Humanism, v. 12, n. 3, p. 333-358 [s.n], 1984.

MORGAN, Sue. Women, Religion and Feminism in Britain, 1750-1900. Basingstoke: Palgrave Macmillan, 2002.

MUÑOZ, Gema Martín. Islam, modernism and the West. Cultural and political relations at the end of the millennium. Nova York: Tauris Publishers, 1999.

NUSSBAUM, Martha C. A plea for difficulty. In: eds. COHEN, Joshua; HOWARD, Matthew; NUSSBAUM, Martha. Is Multiculturalism Bad for Women? Susan Moller Okin with Respondents. Princeton: Princeton University Press, p. 105-114, 1999.

NUSSBAUM, Martha C. The New Religious Intolerance. Overcoming the Politics of Fear in an Anxious Age. Cambridge, MA: The Belknap Press of Harvard University Press, 2012.

PAGIS, Michal. Religious self-constitution: A relational perspective. In: eds. BENDER, Courtney; LEVITT, Peggy. Religion on the Edge: De-Centering and Re-Centering the Sociology of Religion. Oxford: Oxford University Press, p. 92-114, 2013.

PEW RESEARCH CENTER. The Future Global Muslim Population: Projections for 20102030. Forum on Religion \& Public Life, 2011.

PREDELLI, Line Nyhagen et al. Citizenship is not a word I use: How women's movement activists understand citizenship. In: eds. Halsaa, B.; Roseneil, S.; Sümer, S. Remaking Citizenship in Multicultural Europe: Women's Movements, Gender and Diversity. Basingstoke: Palgrave Macmillan, p. 188-212, 2012.

PREDELLI, Line Nyhagen. Issues of Gender, Race, and Class in the Norwegian Missionary Society in Nineteenth Century Norway and Madagascar. Nova York: The Edwin Mellen Press, 2003.

PREDELLI, Line Nyhagen; HALSAA, Beatrice. Citizenship, Gender and Diversity: Women of Faith, Gender Equality and Feminism. Londres: Palgrave Macmillan, 2016.

RAMADAN, Tariq. Western Muslims and the Future of Islam. Oxford: Oxford University Press, 2004.

REILLY, Niamh. Rethinking the interplay of feminism and secularism in a neo-secular age. Feminist Review, v. 97, n. 1, p. 5-31, mar. 2011.

tledge, 2013.

SCRIVER, Stacey. Religion, Gender, and the Public Sphere. Nova York: Rou- 
RINALDO, Rachel. Pious and critical: Muslim women activists and the question of agency. Gender \& Society, v. 28, n. 6, p. 824-846, set. 2014.

ROSADO-NUNES, Maria José. Feminismo, gênero e religião - os desafios de um encontro possível. Estudos de Religião, v. 31, n. 2-7, mai./ago. 2017.

SAHGAL, Gita; YUVAL-DAVIS, Nira. Refusing Holy Orders: Women and fundamentalism in Britain. Londres: Virago Press, 1992.

SAIVING, Valerie. The Human Situation: A Feminine View. In: eds. CHRIST, Carol; PLASKOW, Judity. Womanspirit Rising: A Feminist Reader in Religion. San Francisco: Harper \& Row, 1979.

SALEM, Sara. Feminist critique and Islamic feminism: The question of intersectionality. The Postcolonialist, v. 1, n. 1, nov. p. 1-8, 2013.

SCOTT, Joan W. The Politics of the Veil. Princeton and Oxford: Princeton University Press, 2007.

SMUCKER, Philip. The meaning of a scarf: Turkish students fight to wear Islamic head coverings. U.S. News \& World Report, v. 124, n. 10, p. 31, mar. 1998.

SONBOL, Amira El-Azhary; ABUGIDEIRI, Hibba. Selected articles from Daughters of Abraham: Feminist Thought in Judaism, Christianity and Islam, Gainesville: University Press of Florida, 2001.

STANTON, Elizabeth Cady. The Woman's Bible. Project Gutenberg, 1989. Disponível em: <https://www. gutenberg.org/ebooks/9880>. Acesso em: 12 jan. 2018.

TONG, Rosemarie. Feminist Thought: A Comprehensive Introduction. Londres: Routledge, 1990.

WADUD, Amina. Qur'an and Woman. Oxford and Nova York: Oxford University Press, 1999.

. Inside the Gender Jihad: Women's Reform in Islam. Oxford: Oneworld, 2006.

WALKER, Rebecca. Becoming the Third Wave, 1992. Disponível em: https://pols218.wikispaces. com/file/view/ Walker+-+ Becoming+the+Third+Wave.pdf. Acesso em: 12 mai. 2018. WOODHEAD, Linda. Women and Religion. In: eds. WOODHEAD, Linda; PARTRIDGE, Christopher. Religions in the Modern World. Londres: Routledge, 2002.

. The turn to life in contemporary theology and spirituality. In: Spirituality and society in the new millennium. Brighton: Sussex Academic Press, p. 110-123, 2001.

YAZBECK-HADDAD, Yvonne. The Dynamics of Islamic Identity in North America. In: eds. YAZBECK-HADDAD, Yvonne; ESPOSITO, John Louis. Muslims on the Americanization. Nova York: Oxford University Press, p. 19- 46, 1998.

YUVAL-DAVIS, Nira. Belonging and the politics of belonging. Journal Patterns of Prejudice, v. 40, n. 3, p. 197-214, ago. 2006. 
ŽARKOV, Dubravka. Reflecting on faith and feminism. European Journal of Women's Studies, v. 22, n. 1, p. 3-6 [s.n], 2015.

ZION-WALDOKS, Tanya. Politics of devoted resistance: Agency, feminism, and religion among Orthodox Agunah Activists in Israel. Gender \& Society, v. 29, n. 1, p. 73-97, set. 2014.

Submetido em: 21-9-2018

Aceito em: 22-11-2018 